doi: $10.15407 /$ ujpe62.02.0140

N. GEMECHU, T. SENBETA, B. MESFIN, V.N. MAL'NEV

Addis Ababa University, Department of Physics

(P. O. Box 1176, Addis Ababa, Ethiopia; e-mail: ngjourn@gmail.com)

\title{
THERMOLUMINESCENCE FROM SILICON QUANTUM DOTS IN THE TWO TRAPS-ONE PACS 73.21.La, 73.63.kv RECOMBINATION CENTER MODEL
}

\begin{abstract}
A model of the first and general order kinetics describing the thermoluminescence (TL) from silicon quantum dots consisting of two active electron trap levels and one recombination center is proposed. The two trap levels are located at different trap depths beneath the edge of the conduction band. The rate equations corresponding to each trap level allow us to numerically simulate the variation of the concentration of electrons in the two traps and the TL intensity as a function of the temperature for quantum dots 2-8 $\mathrm{nm}$ in diameter. It is shown that the intensity increases with decreasing in the dot size, indicating that the quantum confinement effect enhances the radiative recombination rate. The two peaks of the intensity correspond to the two different active electron trap levels. With an increase in the dot size, the peaks of the intensity corresponding to the deepest trap shift to the high temperature region. The variation of the concentration of electrons in the traps is given, and this result bridges the experimental gap, where the TL glow curves are generated, and the variation of the concentration of electrons in traps is unknown.

Ke ywords: thermoluminescence, quantum dots, radiative recombination, retrapping.
\end{abstract}

\section{Introduction}

Thermoluminescence (TL) is the emission of light from materials under heating provided that they have previously absorbed the energy of irradiation [14]. The primary agents for the induction of TL in a material are the ionizing radiation, namely X-rays, or radiation from radioactive elements, to which the sample is pre-exposed. In some materials, ultraviolet light may also excite TL. When the sample is subsequently warmed, luminescent light is emitted. The warming stimulates the release of a stored energy in the sample due to the pre-exposure to the ionizing radiation. There are three conditions necessary for the production of TL. First, the material must be a semiconductor or insulator. Second, the material must store some energy during irradiation. Third, the TL emission is triggered by heating the material. The fundamental principles that govern TL are basically the same as those that govern all luminescence processes. In this way, TL is one of a large family of luminescence phenomena $[1,2]$.

(C) N. GEMECHU, T. SENBETA, B. MESFIN, V.N. MAL'NEV, 2017
The light emission from silicon quantum dots is an active research area because of its potential applications in the silicon-based optoelectronic devices [5-8]. The efficiency of the silicon light emitting devices can be increased with the help of various mechanisms. In particular, the possible increase in the intensity of TL from quantum dots caused by the confinement has been studied in [9-10]. It was shown that the confinement increases the probability of radiative recombination and enhances the intensity of TL.

A quantum confined structure is one, in which the motion of carriers (electron and hole) are confined in one or more directions by potential barriers. In quantum dots (QDs), the charge carriers are confined in all three dimensions, and the spatial extent of the electronic wave function is comparable with the particle size. It was shown that the confinement increases the probability of radiative recombination and enhances the intensity of TL. The efficiency of TL from quantum dots is enhanced, because of two main reasons. First, the quantum confinement effect causes an increase in the number of surface states (because of the high surface to volume ratio); so that the particles may provide more accessible carriers (holes and elec-

ISSN 2071-0194. Ukr. J. Phys. 2017. Vol. 62, No. 2 
trons) for the TL recombination. Second, the wave functions of electrons and holes in nano-particles are overlapped effectively, which results in the increase of their radiative recombination probability $\left(A_{r}\right)[9-10]$.

Various models have been used by many research groups to study TL from various materials. The simplest possible model that has been used to describe the process, by which materials emit light when heated, involves two localized levels: an isolated electron trap and a recombination center. This approach is commonly called the one-trap-one-recombination center (OTOR) model [2, 11]. Another model, which assumes one active electron trap, one thermally disconnected deep trap that cannot be thermally activated, and one recombination center has also been used. This model is called the interactive-multitrapsystem (IMTS) model [12]. Basically, in experiments, we have often more than one active electron trap taking part in the TL process.

In this work, a model of TL containing two isolated active electron traps and one recombination center is presented. It can be called the two-trapsone-recombination center (TTOR) model. We consider silicon quantum dots of different sizes with sizedependent radiative recombination rate and study a variation of the concentration of electrons on traps and the TL intensity. Moreover, the variation of the concentration of electrons in each trap is investigated.

\section{Statement of the Problem}

Let us consider the following energy band scheme having three localized levels (Fig. 1). The two levels act as traps $\left(T R_{1}\right.$ and $\left.T R_{2}\right)$, and the other one acts as a recombination center $(\mathrm{R})$. The absorption of the radiation energy greater than the band gap energy results in the ionization of valence electrons, producing free electrons in the conduction band and free holes in the valence band, respectively (transition 1 ).

The electrons and holes may either recombine with each other or become trapped at the trap centers. In order that the recombination occur, holes become trapped firstly at centers (R) (transition 7). The recombination takes place via the annihilation of trapped holes by free electrons (transition 6 ). If the recombination transition is assumed to be radiative, then luminescence will result. The free electrons may also become trapped at levels $T R_{1}$ and $T R_{2}$ (transitions 2 and 4 ). In this case, the recombination

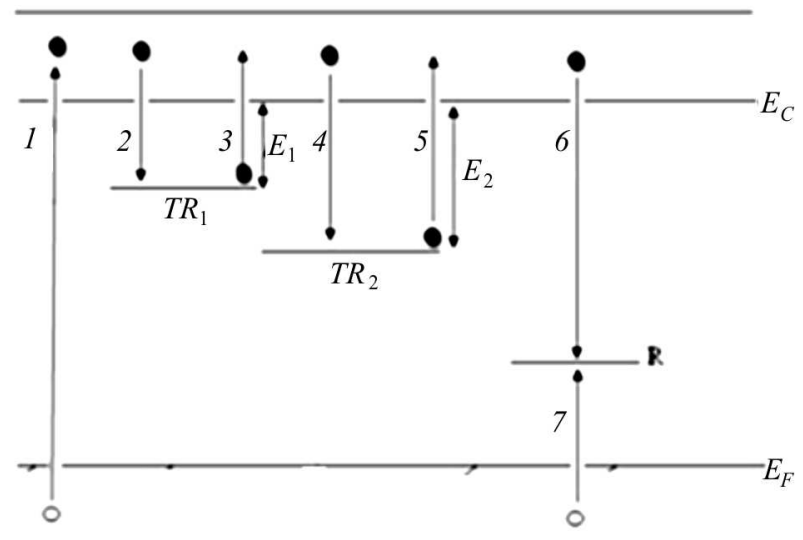

Fig. 1. Three-level model for thermoluminescence. Allowed transitions: ionization (1); trapping (2), (4), and (7); thermal release (3) and (5); radiative recombination and emission of light $(6)$

can only take place, if the trapped electrons absorb enough energies, $E_{1}$ and $E_{2}$, respectively, to be released back to the conduction band (transitions 3 and 5 ), from where the recombination is possible. In other words, TL occurs, when the trapped electrons absorb enough energy in the form of heat to be released back to the conduction band, from where the recombination of electrons and holes is possible. The energy required for the trapped electrons to be released back to the conduction band is called the trap depth (activation energy). Next, we write down the equations of the second-order kinetics.

Now, we consider two active electron traps with energy levels $E_{1}$ and $E_{2}$ below the edge of the conduction band. The rate equations can be written as

$\frac{d n_{1}}{d t}=-s_{1} n_{1} \exp \left\{-\frac{E_{1}}{k T}\right\}+n_{c} A_{1}\left(N_{1}-n_{1}\right)$,
$\frac{d n_{2}}{d t}=-s_{2} n_{2} \exp \left\{-\frac{E_{2}}{k T}\right\}+n_{c} A_{2}\left(N_{2}-n_{2}\right)$,
$\frac{d n_{c}}{d t}=s_{1} n_{1} \exp \left\{-\frac{E_{1}}{k T}\right\}+s_{2} n_{2} \exp \left\{-\frac{E_{2}}{k T}\right\}-$
$-n_{c}\left[A_{1}\left(N_{1}-n_{1}\right)+A_{2}\left(N_{2}-n_{2}\right)+A_{r} n_{h}\right]$.

Here, $n_{i}(i=1,2)$ is the concentration of trapped electrons on the levels $E_{i}\left(\mathrm{~cm}^{-3}\right), N_{i}(i=1,2)$ is the total concentration of traps on the levels $E_{i}\left(\mathrm{~cm}^{-3}\right)$, $k$ is the Boltzmann constant; $s_{i}$ is the probability per unit time of an electron to escape from the $i$ th trap, $A_{i}$ is the retrapping probability on the $i$-th 


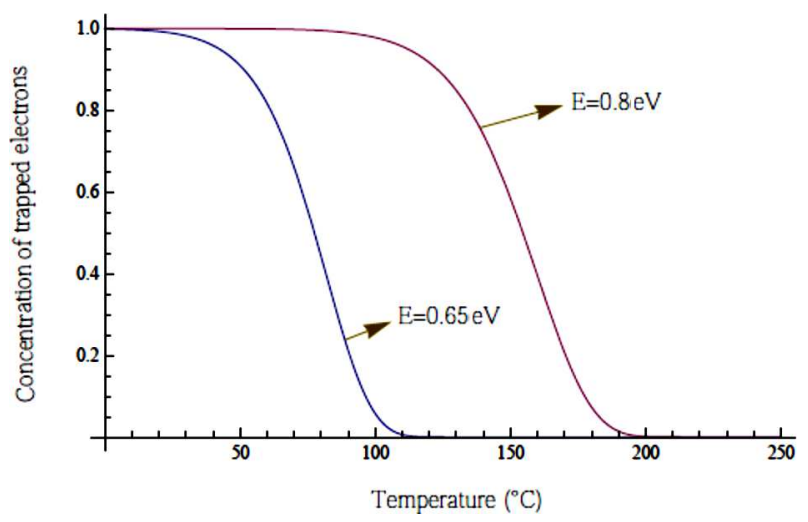

Fig. 2. Normalized concentration of electrons $n_{1}(T)$ and $n_{2}(T)$ in the first trap $\left(E_{1}=0.65 \mathrm{eV}\right)$ and the second one $\left(E_{2}=0.8 \mathrm{eV}\right)$ versus the temperature $T\left(\right.$ in $\left.{ }^{\circ} \mathrm{C}\right)$ for the first-order kinetics with the following values of parameters: $n_{1}(0)=n_{2}(0)=10^{15} \mathrm{~cm}^{-3}, \beta=1{ }^{\circ} \mathrm{C} / \mathrm{s}, s_{1}=s_{2}=10^{8} \mathrm{~s}^{-1}$

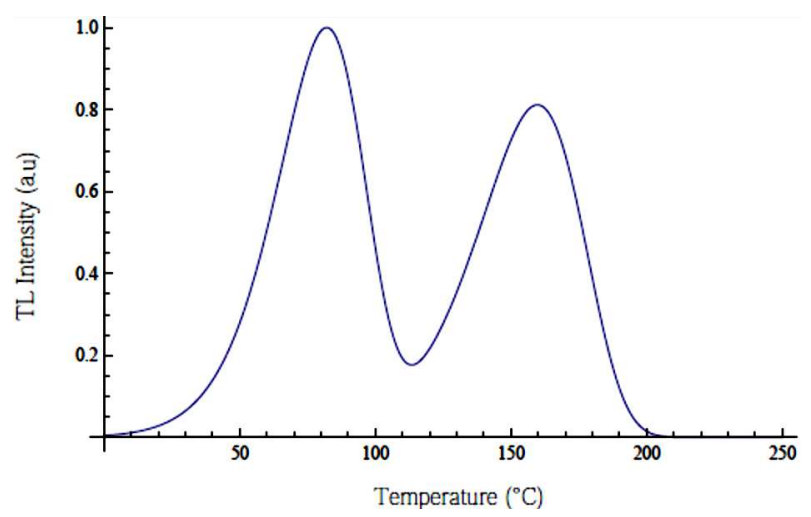

Fig. 3. TL intensity in arbitrary units versus the temperature $T$ for the first-order kinetics with the same parameters as in Fig. 2

energy level $\left(\mathrm{cm}^{3} \mathrm{~s}^{-1}\right), n_{c}$ and $n_{h}$ are the concentration of electrons in the conduction band and holes in the valence band, respectively, $\left(\mathrm{cm}^{-3}\right)$, and $A_{r}$ is the electron-hole radiative recombination probability $\left(\mathrm{cm}^{3} \mathrm{~s}^{-1}\right)$. System (1)-(3) is closed by the quasineutrality condition

$n_{1}(t)+n_{2}(t)+n_{c}(t)=n_{h}(t)$.

Basically, the temperature of the system depends on the time $t$, i.e., $T=T(t)$. This dependence is controlled by conditions of the experiment. Generally acceptable is the linear heating rate

$T(t)=T_{0}+\beta t$, where $\beta$ is the heating rate. The system of equations (1)-(5) presents the rate equations governing the process of TL. The intensity of TL is given by

$I(T)=A_{r} n_{h}(T) n_{c}(T)$.

The above-presented system of equations is nonlinear with varying coefficients. It cannot be solved analytically in the general case. Next, we consider two generally accepted approaches of studying the kinetics of TL.

\section{First-Order Kinetics}

The simplest approach, which allows one to solve the system of equations analytically, is called the firstorder kinetics. It assumes that the recombination is highly dominant over the retrapping and obtained by neglecting the coefficients $A_{1}$ and $A_{2}$. In this case, Eqs. (1) and (2) are independent and their solutions with account for $(5)$ can be written as

$n_{i}(T)=n_{i 0} \exp \left\{-\frac{s_{i}}{\beta} \int_{T_{0}}^{T} \exp \left\{-\frac{E_{i}}{k T}\right\} d T\right\}, \quad i=1,2$,

where $n_{i 0}$ are the initial concentrations of electrons in the traps. It is generally accepted that the density number of electrons in the conduction band $n_{c}(t)$ is a slow function of the time and is practically a constant on the typical times of TL:

$\frac{d n_{c}}{d t} \approx 0$

Substituting (8) in (3) with regard for (6) and (7), we obtain the intensity of TL from each trap in the first-order kinetics:

$I(T)=n_{i 0} s_{i} \exp \left\{-\frac{E_{i}}{k T}\right\} \times$

$\times \exp \left\{-\frac{s_{i}}{\beta} \int_{T_{0}}^{T} \exp \left\{-\frac{E_{i}}{k T}\right\} d T\right\}$.

The graphs depicting the concentration of electrons on the traps $n_{1}, n_{2}$ and the intensity of TL versus the temperature $T$ for the typical parameters of the TL systems are presented in Figs. 2 and 3 , respectively. Figure 2 shows that the first trap

ISSN 2071-0194. Ukr. J. Phys. 2017. Vol. 62, No. 2 
( $E_{1}=0.65 \mathrm{eV}$ ) is activated at $T_{1} \approx 40{ }^{\circ} \mathrm{C}$ and the second one $\left(E_{2}=0.8 \mathrm{eV}\right)$ at $T_{2} \approx 100{ }^{\circ} \mathrm{C}$. Figure 3 shows two maxima of the intensity of TL in arbitrary units at the temperatures corresponding to the thermal activation of the traps. The TL intensity maximum for the first trap is higher than that for the second one, because $E_{1}<E_{2}$. The maxima of intensity curves of the traps with close energies $E_{1} \approx E_{2}$ get closer. For particular value of $E_{2}-E_{1}$, they practically merge.

To consider the effects of electron retrapping, one has to use a more general approach that is called the general order kinetics.

\section{General Order Kinetics}

In this case, the retrapping terms with the coefficients $A_{1}$ and $A_{2}$ are taken into account. This considerably complicates the system of equations (1)-(3) that becomes nonlinear and cannot be solved analytically in general case. We solved our system of equations numerically with the help of Mathematica 8 with the same parameters, as have been used in the previous section. But now, it is necessary to specify the additional parameters: the retrapping probabilities $A_{1}$ and $A_{2}$, and the electron-hole radiative recombination probability $A_{r}$. The latter one depends on the size of a quantum dot. It is clear that the confinement must increase the radiative recombination probability.

For the typical quantum dots, the retrapping probability is of the order of $10^{7} \mathrm{~s}^{-1}$. We choose $A_{1}=$ $=A_{2}=5 \times 10^{7} \mathrm{~cm}^{3} \mathrm{~s}^{-1}$ and ignore the possible corrections associated with the confinement. The coefficient $A_{r}$ depends on the size of a quantum dot. The graph of experimental data on the size dependence of $A_{r}$ of quantum dots $2-8 \mathrm{~nm}$ in diameter is given in [5], and we summarized it in Table. It illustrates the rate of radiative recombination as a function of the quantum dot size for our model. Since the retrapping dominates in this case, we should take the value of retrapping probability greater than the radiative recombination probability.

Figures 4 and 5 show a variation of the concentration of electrons in the traps with activation energies $E_{1}=0.65 \mathrm{eV}$ and $E_{2}=0.8 \mathrm{eV}$, respectively, for quantum dots of various diameters of 2-8 $\mathrm{nm}$ for the general order kinetics. The electrons that are released from the first trap level $(E=0.65 \mathrm{eV})$ can be

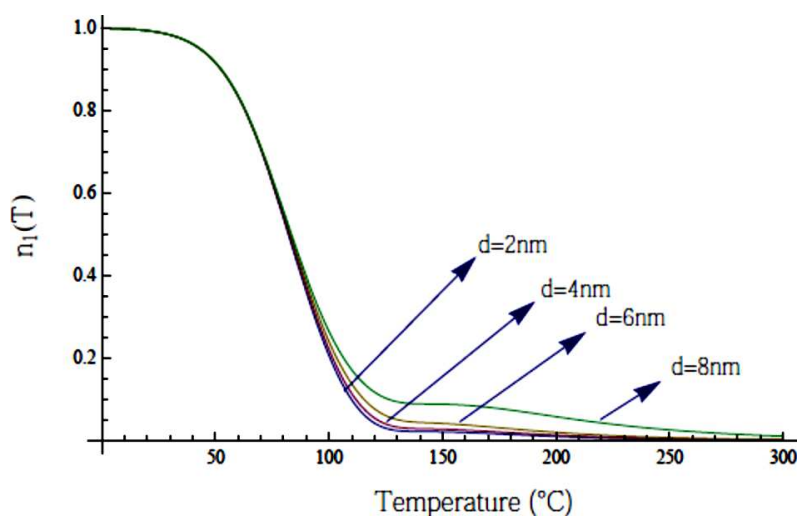

Fig. 4. Numerical simulation of a variation of the concentration of electrons $n_{1}(T)$ in the shallower trap $\left(E_{1}=0.65 \mathrm{eV}\right)$ for the general order kinetics

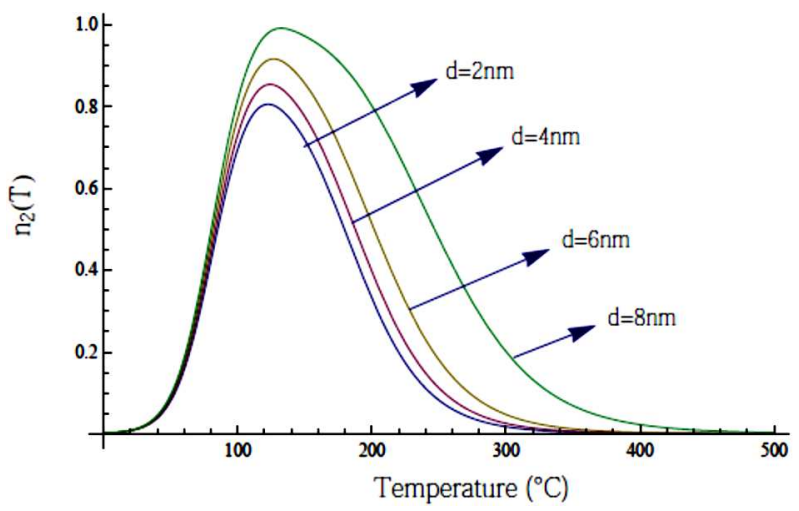

Fig. 5. Numerical simulation of a variation of the concentration of electrons $n_{2}(T)$ in the deeper trap $\left(E_{2}=0.8 \mathrm{eV}\right)$ for the general order kinetics

Approximate values of radiative recombination rate of the quantum dots

\begin{tabular}{|c|c|}
\hline $\begin{array}{c}\text { Diameter of a quantum } \\
\text { dot in nm }\end{array}$ & $\begin{array}{c}\text { Radiative recombination } \\
\text { rate }\left(A_{r}\right){\mathrm{in} \mathrm{cm}^{3} \mathrm{~s}^{-1}}^{-1}\end{array}$ \\
\hline 2 & $2 \times 10^{7}$ \\
4 & $3 \times 10^{6}$ \\
6 & $4 \times 10^{5}$ \\
8 & $5 \times 10^{4}$ \\
\hline
\end{tabular}

retrapped by the deeper trap $(E=0.8 \mathrm{eV})$. This explains an increase in the concentration of electrons in the deeper trap with the temperature, as indicated in Fig. 5. One can see from Figs. 4 and 5 that $n_{1}(T)$ and $n_{2}(T)$ depend on the size of a quantum dot as well. 


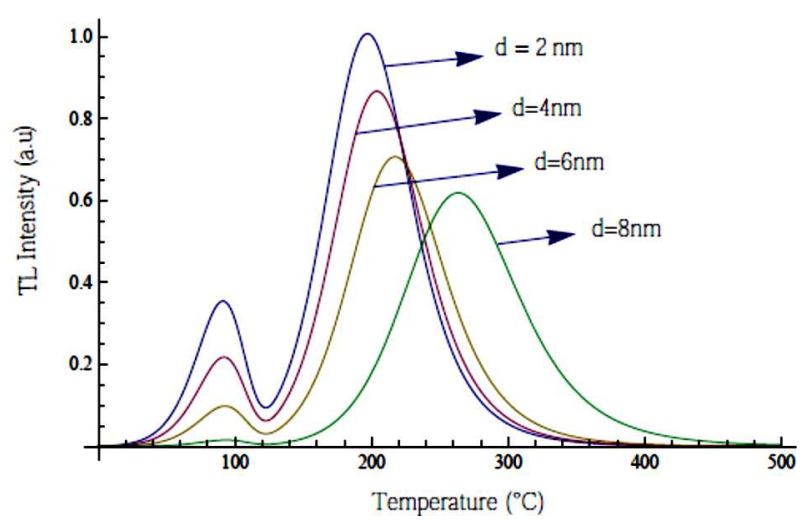

Fig. 6. Numerical simulation of the TL intensity $I$ versus the temperature for the general order kinetics

The Table shows that the number of carriers, which are recombined radiatively per unit time, increases with a decrease in the quantum dot size. Using the data of Table and Eq. (6), we generated the temperature-dependent TL intensity for the dots with diameters in the mentioned range and present it in Fig. 6. The intensity increases with decreasing the dot size, indicating that the quantum confinement effect enhances the radiative recombination rate. There are two TL intensity maxima for each peak, and they correspond to two different active electron trap levels. We also found that positions of the TL maxima for glow curves corresponding to the first trap practically do not shift with the temperature. However, the maximum intensity of the peaks from the second trap significantly shift to high temperatures with increasing the size of quantum dots. The TL peaks of the first trap have lower intensities as compared with those of the peaks corresponding to the second trap (Fig. 6). This can be explained by the fact, that during the excitation of the first trap, only some part of its electrons recombine with holes, by emitting light. However, the majority of electrons are retrapped by the second (deeper) trap. This is indicated in the initial rise in a variation of the concentration of electrons in the deeper trap (Fig. 5).

\section{Conclusion}

The TL glow curves of silicon quantum dots $2-8 \mathrm{~nm}$ in diameter in the model of two active electron traps and one recombination center have been numerically simulated within the frame of the first and general order kinetics. There are two peaks of the TL inten- sity corresponding to the two active electron trap levels. The first order kinetics does not involve the retrapping effects, and the calculated TL intensity does not depend on the quantum dot size. As a result, this approach gives the higher TL intensity as compared with the general order kinetics. We focused on the results obtained within the frame of the general order kinetics approach as more realistic ones.

The results show that the TL intensity increases with decreasing the quantum dot size. This can be explained in terms of the quantum confinement effect. In this work, we account for it with the help of the extrapolation of the experimental data on the probability of radiative transitions on the quantum dot size. We have obtained that the trap with deeper electron level $E_{2}=0.8 \mathrm{eV}$ (we call it the second trap) provides the higher TL intensity as compared to the trap with shallower level $E_{1}=0.65 \mathrm{eV}$ (the first trap), but at higher temperatures. Both traps show an increase in the TL intensity with a decrease in the quantum dots size. We claim that this conclusion will be true for any traps provided that $E_{1}<E_{2}$.

To our mind, the ensemble of quantum dots of two kinds with different sizes and different energies of the trapped electrons may have interesting TL properties and deserves a further study.

This work is financially supported by Addis Ababa University and Mizan-Tepi University.

1. S.W.S. Mckeever. Thermoluminescence of Solids (Cambridge Univ. Press, 1988).

2. V. Pagonis, G. Kitis, C. Furetta. Numerical and Practical Exercises in Thermoluminescence (Springer, 2005).

3. Yu.A. Skryshevskii, V.A. Skryshevskii. Thermally stimulated luminescence in porous silicon. J. Appl. Phys. 89, 2711 (2001) [DOI: 10.1063/1.1344915].

4. C. Furetta. Handbook of Thermoluminescence (Cambridge Univ. Press, 1988).

5. N.M. Abdul-Ameer, M.C. Abdulrida. Direct optical energy gap in amorphous silicon quantum dots. J. Modern Phys. 2, 1530 (2011) [DOI: 10.4236/jmp.2011.212185].

6. K. Dohnalová, T. Gregorkiewicz, K. Kủsová. Silicon quantum dots: surface matters. J. Phys.: Condens. Matter 26, 173201 (2014) [DOI: 10.1088/0953-8984/26/17/173201].

7. S. Martini, L.K. Teles, M. Marques, A.E.B. Marques, A.A. Quivy. Radiative recombination mechanisms of large InAs/GaAs quantum dots. World J. Condens. Matter Phys. 161, 1 (2011) [DOI: 10.4236/wjcmp.2011.14024].

ISSN 2071-0194. Ukr. J. Phys. 2017. Vol. 62, No. 2 
8. E.-C. Cho, M.A. Green, G. Conibeer, D. Song, Y.-H. Cho et al. Silicon quantum dots in a dielectric matrix for allsilicon tandem solar cells. Advances in OptoElectronics 2007, 1 (2007) [DOI: 10.1155/2007/69578].

9. L.R. Singh, S.D. Singh. Particle size effect on TL emission of $\mathrm{ZnS}$ nanoparticles and determination of its kinetic parameters. J. Nanomater. 2012, 1 (2012) [DOI: 10.1155/2012/239182].

10. R. Sharma, B.P. Chandra, D.P. Bisen. Thermoluminescence and optical absorption spectra of ZnS:Mn nanoparticles. Chalcogenide Lett. 6, 251 (2009).

11. V. Pagonis, G. Kitis. Prevalence of first-order kinetics in thermoluminescence materials: An explanation based on multiple competition processes. Phys. Status Solidi B 249, 1590 (2012) [DOI: 10.1002/pssb.201248082].

12. A.M. Sadek, H. M.Eissa, A.M. Basha, G. Kitis. Properties of the thermoluminescence glow peaks simulated by the interactive multiple-trap system (IMTS) model. Phys. Status Solidi B 252, 721 (2015) [DOI: 10.1002/pssb.201451406].

Received 17.06.16
Н. Гемечу, Т. Сенбета, Б. Месфін, В.М. Мальнев

ТЕРМОЛЮМІНЕСЦЕНЦІЯ КВАНТОВИХ ТОЧОК КРЕМНІЮ В МОДЕЛІ ДВІ ПАСТКИ-ОДИН ЦЕНТР РЕКОМБІНАЦІЇ

\section{$\mathrm{P}$ е $з$ ю м е}

Запропоновано модель кінетики першого і довільного порядків термолюмінесценції (ТЛ) квантових точок кремнію, що включає один центр рекомбінації і два різних електронних рівня пасток нижче краю зони провідності. Кінетичні рівняння для кожного рівня дозволяють чисельно моделювати залежність концентрації електронів у пастках і інтенсивності ТЛ від температури для квантових точок 2-8 нм у діаметрі. Показано, що інтенсивність зростає при зменшенні діаметра точок, тобто, ефект квантового утримування збільшує швидкість радіаційної рекомбінації. Два піка інтенсивності відповідають двом різним електронним рівням. Зі збільшенням розміру точок піки, відповідні самому глибокому рівню, зсуваються до області великих температур. Розраховано зміну концентрації електронів у пастках, і цей результат відповідає експериментальним даним по ТЛ тліючого розряду. 